\title{
COVID-19 demonstrates the value of open access What happens next?
}

n the wake of COVID-19, many publish-

ers have tacitly agreed that open access is beneficial to scientific advancement and necessary to move science forward to combat disease. Publishers have committed to open access publication of scientific articles relating to the disease. Some are facilitating rapid and open peer review and fast-tracking the publishing of related research. ${ }^{1}$ Pulitzer Prize-winning journalist Michael Hiltzig refers to this convincing demonstration of the value of open access to scientific research as one of the most important positive disruptions caused by COVID-19. ${ }^{2}$

The World Health Organization (WHO) maintains a global research hub with links to several publisher sites for access to coronavirus research, and the U.S. Centers for Disease Control has compiled a similar list. ${ }^{3}$ Elsevier (and its high-profile journals like Cell and The Lancet), Wiley, SpringerNature, The New England Journal of Medicine, and scores of other publishers and publications have provided open access to COVID-19 research. ${ }^{4}$ Even news magazines like Wired and Medium, which usually allow readers access to a limited number of free articles without a subscription, began providing free unlimited access to stories about COVID-19 shortly after it was classified as a global pandemic. They also offered an invitation to sign up for email updates, as if our anxiety levels were not already high enough. 5 SpingerNature is encouraging researchers to use their
In Review preprint system while articles are being peer-reviewed and to share datasets widely. Many vendors are offering free access to online learning solutions and educational resources for the remainder of the spring semester. Some researchers have chosen to bypass traditional journals altogether, putting their work on disciplinary preprint servers. ${ }^{6}$

While the absence of peer review on these platforms has the potential to widely disseminate misinformation, the robust use of preprint servers by the scientific community has worked to rebut spurious claims, in effect crowdsourcing rapid expert peer-review. ${ }^{7}$ (So no, there is no evidence that COVID-19 was manufactured in a lab. ${ }^{8}$ ) It is also worth noting that Nature's Outbreak Science Rapid PREview server, which was established in response to COVID-19, allows scientists with an ORCID ID to submit a review while reading preprints pulled in from the medRxiv, bioRxiv, and arXiv repositories. ${ }^{?}$

Government officials in the United States, Australia, Brazil, Canada, Germany, India, Italy, Japan, New Zealand, Singapore, South Korea, and the United Kingdom are now

Willa Tavernier is open scholarship resident librarian at Indiana University-Bloomington's Herman B. Wells Library, email: wtavern@iu.edu. AttributionNonCommercial, http://creativecommons.org/licenses /by-nc/4.0/, CC BY-NC

() 2020 Willa Tavernier 
calling for even wider access. ${ }^{10}$ This would encompass the text of journal articles as well as machine-readable text to enable analysis using artificial intelligence, along with research data made available through sources like PubMed Central and WHO's COVID database..$^{11}$ Outside of the realm of scientific publication, the Taiwanese response to the outbreak highlights how easy, free public access to reliable information is beneficial to a robust, effective response across a complex system, which requires the coordination of governance, institutions, individuals, and their varying points and levels of interaction. ${ }^{12}$ Taiwanese analyst Victor (Lin) Pu argues that the "free flow of information is the best treatment for the coronavirus outbreak." 13

At the time this article was written, the current outbreak was expected to subside within a few months, with health authorities using shutdowns, social distancing, and quarantines in an effort to "flatten the curve" of contagion. When the pandemic subsides, where do we go next in academic publishing? Clearly, most stakeholders in this pandemic situation regard knowledge about the disease as an open access common pool resource--a public good that should be freely accessible. Does this change in the absence of a crisis? Is it then acceptable to slow the progress of science? And who has the right to make these decisions? These are issues both of governance and design.

In their work Analyzing the Knowledge Commons, Elinor Ostrom and Charlotte Hess describe an institutional analysis design framework for analyzing governance in common pool resources and then apply that framework to analyzing knowledge as a commons. ${ }^{14}$ They point out that knowledge is a nondiminishing resource, and that greater access to knowledge enhances its value and utility. Ostrom and Hess go on to explain that within any commons there are action arenas or action situations where participants make decisions based on a certain set of characteristics with which they are confronted. They recognize that a knowledge commons is a complex system, and that decisions and outcomes are largely dependent on the varying patterns of interactions within any action arena.

Within that context of knowledge as a common pool resource, the emergence of the COVID-19 pandemic and the need for access to information about the disease presents a new action arena. The response of publishers is not entirely novel, as similar actions were taken by some publishers in response to the SARS outbreak. ${ }^{15}$ However some are of the view that COVID-19 marks a sea change in the way scientists communicate. ${ }^{16}$ Certainly, the participation by Elsevier, Wiley, The Lancet, and Cell Press in the 2020 commitment to share research data and findings relevant to the novel coronavirus (COVID-19) outbreak is novel. In this current action situation, public calls for access to the research by governments and WHO, lessons learned from past outbreaks, and individual actions by researchers have together produced an environment in which all of the major scientific publishers have decided to facilitate the free flow of information, which in turn has accelerated the progress of science to fight the disease. It is a dynamic situation that has established new norms, and the publishers by their actions have validated the argument that where there are barriers to access to such knowledge, the pace of scientific progress decelerates.

The current system of scholarly publishing in which research is restricted by paywalls evolved during the print era, when it became inefficient for scholarly societies to manage production, validation, and distribution of scientific and scholarly research. Commercial publishers could do this at scale, resulting in greater economy and efficiency. However, the cost of access to this information grew to a level considered to be a crisis. ${ }^{17}$ The continuing trend in university cancellations of subscription packages with major publishers indicates that this system may no longer be sustainable. ${ }^{18}$

In a knowledge commons, characterized by what Hess and Ostrom describe as "distributed digital information," different 
economies are at play. Digital distribution via posting on a publisher's website greatly reduces the costs of dissemination. Much of those costs shift to technology for managing access (restricted to subscriber-only), which can be eliminated if open access was the governing paradigm. This is not to say that all costs disappear, for example, the costs of the technical hosting infrastructure and the skilled technicians to maintain it replaces the costs of transport and distribution. However, it must be borne in mind that many scholarly societies and universities already have the basic web infrastructure, and, in some cases the technical staff, in place. These technical characteristics, coupled with the rise of open source publishing software such as Open Journal Systems and Manifold, as well as a community of library publishers, provide alternatives to commercial publishing. ${ }^{19}$ Costs associated with copy editing, marketing, and managing peer review remain. However, it should be noted that the actual costs of peer reviewers in most cases is nil (though rapid peer review models where reviewers are paid appear to be emerging), and various open peer review models may provide the beginnings of an answer to management costs. In addition, systems like Scielo (Scientific Electronic Library Online) illustrate an alternative mechanism of funding the costs of access to research. ${ }^{20}$

Strategies being deployed by the research community to combat COVID-19 give us a proof of concept for what is possible. Elinore Ostrom's groundbreaking research on design principles for resilient common pool resource institutions, which earned her a Nobel Prize in economics, lays out design principles for how we might build new institutions within the knowledge commons. ${ }^{21}$ Those principles suggest that those affected by the rules governing a resource should have the right to change the rules, that there should be accountability in the system and graduated sanctions, as well as mechanisms for rapid resolution of conflict. The Institutional Analysis Design Framework (IAD), as applied to knowledge as a commons by Hess and Ostrom, adds to those design principles to include considerations of equity, transparency, and adaptability.

How might these design principles and the strategies that are emerging during the COVID-19 pandemic work together? The publication, criticism, and withdrawal of a paper on the open access disciplinary preprint server bioRxiv, which suggested that COVID-19 was manmade, is a clear example of these principles at work. ${ }^{22}$ The preprint has since been updated with a statement that, "This paper has been withdrawn by its authors. They intend to revise it in response to comments received from the research community on their technical approach and their interpretation of the results."

The culture of collaboration in the scientific disciplines within which COVID-19 research lies, and specifically the trust networks that have developed around collaborative research and the function of open access preprint servers like bioRxiv and medRxiv, are important factors. Scholars agree that robust and enduring trust networks are essential to set priorities, make effective decisions in rapidly changing environments, solve problems, and build resilient institutions to manage common pool resources in general and the infrastructure for scholarly dissemination in particular. ${ }^{23}$ However, the current hypervisibility of the culture of collaboration in the hard sciences should not lead us to assume that these are the only disciplines in which this level of open scholarship is possible.

While other fields of study will have different sociocultural and institutional structures, different institutional and geographic contexts, and different discourses in use, similar trust networks for collaboration have emerged within and across disciplines. These have been operative in computer programming (in particular the free and open source software movement), architecture (specifically in the field of participatory design), the humanities (in particular, the digital humanities), library and information science, and other social sciences. ${ }^{24}$ Moreover, the intersection of 
these disciplines is the common goal of advancing the knowledge and understanding in their scholarly field. Therefore, the system for scholarly communication ought to promote such advancement-the COVID-19 pandemic shows us that open access publishing is an efficient, effective means of doing this.

Within the knowledge commons characterized by distributed digital knowledge with the different economies at play, and with the developing trust networks around open scholarship, it becomes possible to question whether after COVID-19 subsides governments, scientists, and global institutions will find it acceptable for publishers to continue to put paywalls around research-- decelerating scientific, scholarly, and social advancement. It becomes possible to question whether commercial publishers should govern, i.e., be the principal decision-makers about, and gatekeepers of, access to knowledge. Most importantly, it becomes possible to question what type of scholarly publishing system we (collectively as a society) want, and to design it accordingly.

\section{Notes}

1. "Statement on Data Sharing in Public Health Emergencies," Wellcome Trust, accessed March 17, 2020, https://wellcome. ac.uk/press-release/statement-data-sharing -public-health-emergencies; "COVID-19," accessed March 16, 2020, https://www.cell. com/2019-nCOV; Michael A. Johansson and Daniela Saderi, "Open Peer-Review Platform for COVID-19 Preprints," Nature 579, no. 29 (2020), https://doi.org/10.1038/d41586-020 -00613-4; "Novel Coronavirus (2019-NCoV) Outbreak," PLOS, accessed March 16, 2020, http://blogs.plos.org/plos/?p=9042.

2. Michael Hiltzig, "COVID-19 Could Kill the for-Profit Science Publishing Model. That Would Be a Good Thing," Los Angeles Times, March 3, 2020, https://www.latimes.com /business/story/2020-03-03/covid-19-open -science.

3. "Global Research on Coronavirus Disease (COVID-19)," World Health Or- ganization (WHO), accessed March 16, 2020, https://www.who.int/emergencies /diseases/novel-coronavirus-2019/global -research-on-novel-coronavirus-2019-ncov; "COVID-19 Databases and Journals," accessed March 16, 2020, https://www.cdc.gov/library /researchguides/2019novelcoronavirus /databasesjournals.html.

4. See "Novel Coronavirus Information Center," Elsevier Connect, accessed March 16, 2020, https://www.elsevier.com/connect /coronavirus-information-center; "COVID-19 Resource Center," The Lancet, accessed March 16, 2020, https://www.thelancet.com /coronavirus; "Novel Coronavirus-Wiley Online Library," Wiley, accessed March 16, 2020, https://novel-coronavirus.onlinelibrary. wiley.com/; "Coronavirus | Springer Nature | For Researchers," Springer Nature, accessed March 16, 2020, https://www.springernature. $\mathrm{com} / \mathrm{gp} /$ researchers/campaigns/coronavirus; "Coronavirus (Covid-19)—NEJM," New England Journal of Medicine, accessed March 16, 2020, https://www.nejm.org /coronavirus.

5. Louise Matsakis, "How to Stop a Coronavirus Anxiety Spiral," Wired, March 13, 2020, https://www.wired.com/story/how-to -stop-coronavirus-anxiety-spiral.

6. Adam Rogers, "Coronavirus Research Is Moving at Top Speed-With a Catch," Wired, January 31, 2020, https://www.wired.com /story/coronavirus-research-preprint -servers/.

7. Kai Kupferschmidt, "'A Completely New Culture of Doing Research': Coronavirus Outbreak Changes How Scientists Communicate," Science, February 26, 2020, https://www.sciencemag.org/news/2020/02 /completely-new-culture-doing-research -coronavirus-outbreak-changes-how -scientists.

8. Chuan Xiao, et al., "HIV-1 Did Not Contribute to the 2019-NCoV Genome," Emerging Microbes \& Infections 9, no. 1 (2020): 378-81, https://doi.org/10.1080 /22221751.2020.1727299.

9. "Global Research on Coronavirus Disease (COVID-19)," WHO. 
10. Klint Finley, "Global Officials Call for Free Access to Covid-19 Research," Wired, March 13, 2020, https://www.wired.com /story/global-officials-call-free-access-covid -19-research/.

11. PubMed Central homepage, accessed March 19, 2020, https://www.ncbi. nlm.nih.gov/pmc/.

12. Cindy Sui, "What Taiwan Can Teach the World on Fighting the Coronavirus," NBC News, March 10, 2020, https:// www.nbcnews.com/health/health-news /what-taiwan-can-teach-world-fighting -coronavirus-n1153826. This article reports that Taiwan took the stance that “. . . only when information is transparent, and people have sufficient medical knowledge, will their fear be reduced," requiring television and radio stations to broadcast hourly public-service announcements about the coronavirus, including how it spreads and how people should prevent infection.

13. Victor (Lin) $\mathrm{Pu}$, "The Coronavirus Outbreak: How Democratic Taiwan Outperformed Authoritarian China," The Diplomat, February 27, 2020, https://thediplomat. com/2020/02/the-coronavirus-outbreak-how -democratic-taiwan-out performed -authoritarian-china/.

14. Charlotte Hess and Elinor Ostrom, "Analyzing the Knowledge Commons" in Understanding Knowledge as a Commons: From Theory to Practice, eds. Charlotte Hess and Elinor Ostrom (MIT Press: Cambridge, MA, 2007), 41-81.

15. "Statement on Data Sharing in Public Health Emergencies," Wellcome Trust, February 1, 2016, https://wellcome.ac.uk/ press-release/statement-data-sharing-publichealth-emergencies.

16. Johansson and Saderi; "Global Research on Coronavirus Disease (COVID-19),"WHO; Kupferschmidt; see also Hiltzig.

17. Martha Kyrillidou and Mark Young, eds., "ARL Statistics 2004-2005," Association of Research Libraries Statistics, 2006, https://publications.arl.org/ARL -Statistics-2004-2005/10.
18. "Big Deal Cancellation Tracking," SPARC, accessed March 16, 2020, https://sparcopen.org/our-work/big-deal -cancellation-tracking/.

19. "Library Publishing Coalition | Academic \& Research Libraries Engaged in Scholarly Publishing," accessed March 16, 2020, https://librarypublishing.org/.

20. "SciELO-Scientific Electronic Library Online," accessed March 16, 2020 , http://www.scielo.br/.

21. Elinor Ostrom, Governing the Commons: The Evolution of Institutions for Collective Action (Cambridge University Press: New York: NY, 1990).

22. Pradhan et al., "Uncanny Similarity of Unique Inserts in the 2019-NCoV Spike Protein to HIV-1 Gp120 and Gag," bioRxiv, Preprint. Evolutionary Biology, January 31, 2020, https://www.biorxiv.org/content/10. 1101/2020.01.30.927871v1?versioned=true. Many of the 112 comments on this original version of the article pointed to flaws in the authors' arguments and research that debunked its thesis, even prior to the article by Xiao et al., precipitating its withdrawal.

23. Ostrom; Lorcan Dempsey, Constance Malpas and Mark Sandler, "Operationalizing the BIG Collective Collection: A Case Study of Consolidation vs Autonomy," OCLC Research, October 24, 2019, https:// doi.org/10.25333/jbz3-jy57; Roger Schonfield, "Restructuring Library Collaboration," Ithaka S+R, March 6, 2019, https://sr.ithaka.org/publications/restructuring-library-collaboration/.

24. Miguel Asencio, "Collaborating for Success: The Digital Library of the Caribbean," Journal of Library Administration 57, no. 7 (2017): 818-825, https://doi.org/10.1080 /01930826.2017.1362902; Charles M. Schweik "Free/Open-Source Software as a Framework for Establishing Commons in Science," in Understanding Knowledge as a Commons, eds. Charlotte Hess and Elinor Ostrom, eds. (MIT Press: Cambridge, MA, 2007), 277-310; Giacomo Poderi, "Sustaining Platforms as Commons: Perspectives on Participation, Infrastructure, and Governance," CoDesign, 15, no. 3 (2019), 243-55, https://doi.org/10. 1080/15710882.2019.1631351. z 